\title{
Right ventricle in pulmonary embolism: 3D echocardiography analysis
}

\section{(D)Fatmir Ferati*, (D)Anida Ferati, (i) Mentor Karemani, DArdian Preshova}

University Hospital Tetovo Tetovo, Republic of North Macedonia
RECEIVED:

February 28, 2019

ACCEPTED:

March 24, 2019

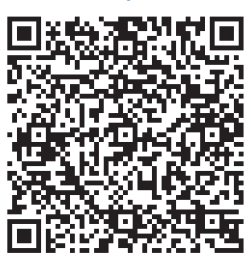

$\square$ Cardiologia Croatica 2019;14(3-4):102.
KEYWORDS: pulmonary embolism, echocardiography.

CITATION: Cardiol Croat. 2019;14(3-4):102-3. | https://doi.org/10.15836/ccar2019.102

*ADDRESS FOR CORRESPONDENCE: Fatmir Ferati, University Hospital Tetovo, Derish Cara bb, 1200 Tetovo, Republic of North Macedonia. / Phone: +389-70-224138 / E-mail: fatmir_ferati@yahoo.com

ORCID: Fatmir Ferati, https://orcid.org/0000-0001-8189-316X • Anida Ferati, https://orcid.org/0000-0002-4243-5569 Mentor Karemani, https://orcid.org/0000-0001-6626-6504 • Ardian Preshova, https://orcid.org/0000-0003-2416-6593

IIIIIIIIIIIIIIIIIIIIIIIIIIIIIIIIIIIIIIIIIIIIIIIIIIIIIIIIIIIIIIIIIIIIIIIIIIIIIIIIIIIIIIIIIIIIIIIIIIIIIIIIIIIIIIIII

Introduction: The purpose of the study is, analysis of the right ventricular (RV) function in patients with pulmonary embolism proven by the clinical presentation and CT angiography of the pulmonary arteries, which are positive in this disease. Verification of echocardiography changes in these emergency cases, enables early diagnosis of this condition as well as its efficient treatment.,2

Methods and Results: A total of 20 patients with pulmonary embolism, 59 years old ( $59+/$ - 11 years) were screened, based on the clinical observation and visualization of thrombotic formations in the pulmonary arteries, with CT angiography. The group of persons without cardiovascular disease is consisted of a total of 50 people, 55.3 years old $(55.3+/-17)$, that were selected randomly. In Table 1 results of the RV function in the population without a verified cardiovascular disease have been taken. A significant increase of EDV of RV (157ml vs. $79 \mathrm{ml})$ was recorded, registered by 3D measurements, in the group with PE (Figure 1). Reduction in the EF of RV in the PE group (57.3\% vs $27.8 \%$ ), was recorded in the first days. TAPSE of RV, is reduced in the PE group (18.6 $\mathrm{mm}$ vs. $10.5 \mathrm{~mm}$ ) along with the reduction of (FAC) of RV (47.66 vs. $22.11 \%$ ). LSS (septal wall) shows its reduction from $-18.9 \%$ to $-12.8 \%$, while the free wall LS (LSF) function is much more pronounced in the group of pulmonary PE patients, and it has been reduced from $-31.5 \%$ to $-11.6 \%$ in the PE group, which is one of the echocardiographic characteristics of the PE (Figure 2)

TABLE 1. Results of the right ventricular function in the population without a verified cardiovascular disease.

\begin{tabular}{llllllll} 
& $\begin{array}{l}\text { EDV of RV } \\
\text { in } \mathbf{~ m l}\end{array}$ & $\begin{array}{l}\text { EF of RV } \\
(\%)\end{array}$ & $\begin{array}{l}\text { TAPSE RV } \\
\mathbf{m m}\end{array}$ & $\begin{array}{l}\text { Fac } \\
(\%)\end{array}$ & $\begin{array}{l}\text { Septal LS } \\
(-\%)\end{array}$ & $\begin{array}{l}\text { Free wall LS } \\
(-\%)\end{array}$ & $\begin{array}{l}\text { Basal } \\
\text { dimension of } \\
\text { RV (mm) }\end{array}$ \\
\hline b.0 & 79.14 & 57.25 & 18.6 & 47.66 & 18.89 & 31.49 & 31.24 \\
\hline TE pulmonum & 157.367 & 27.86 & 10.57 & 22.11 & 12.81 & 11.668 & 39.72 \\
\hline
\end{tabular}

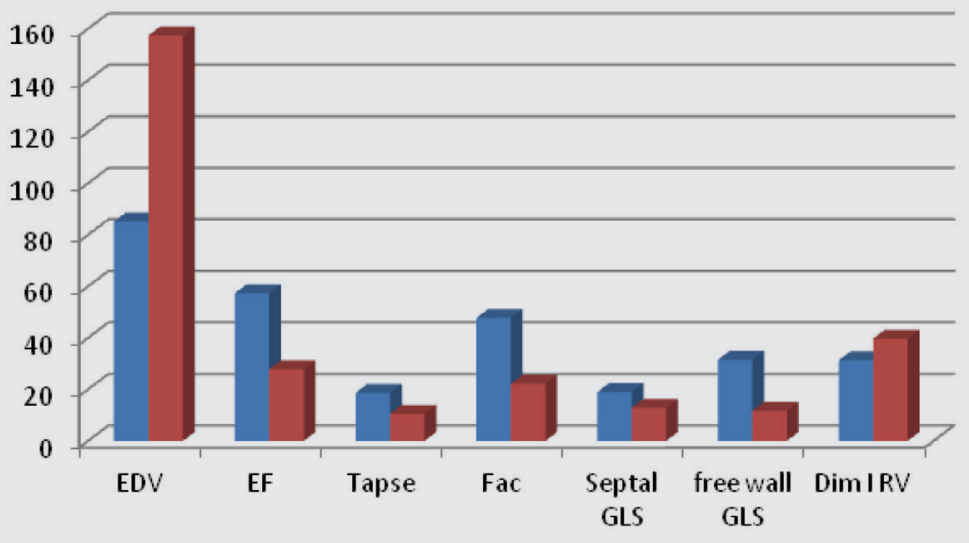

b.o

- TE pulmonum 

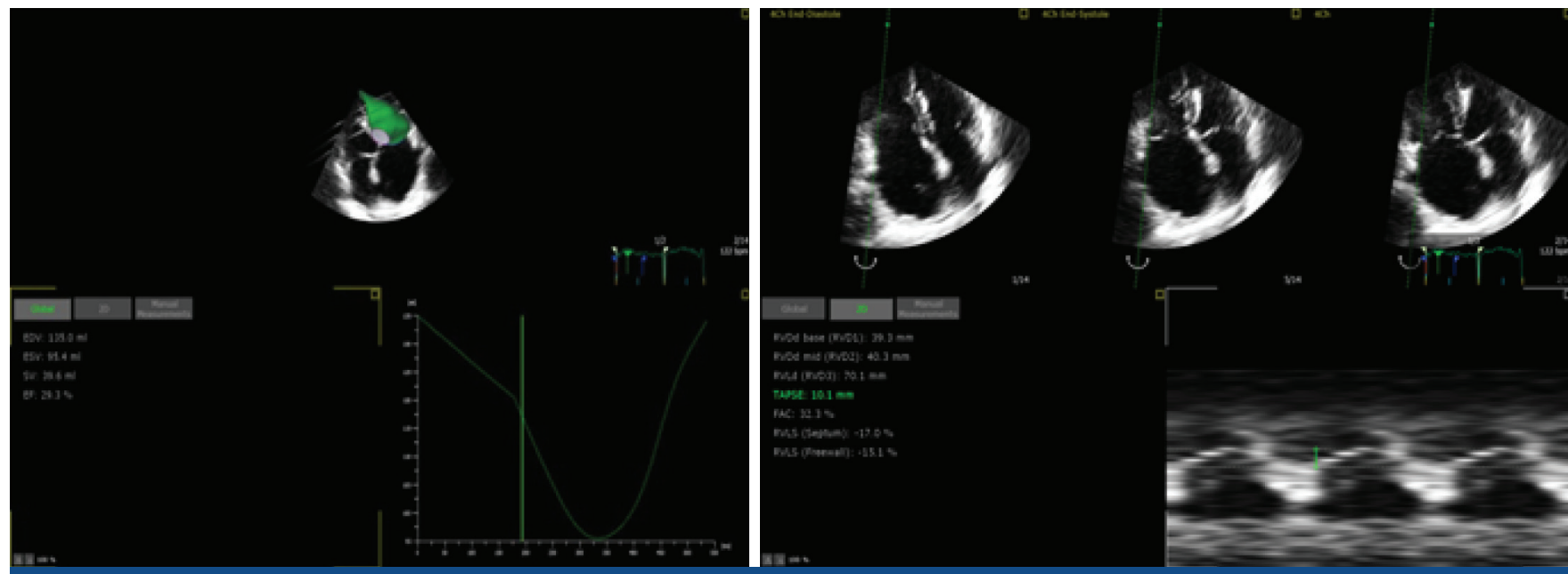

FIGURE 1. Pulmonary TE in acute phase (3D RV function).
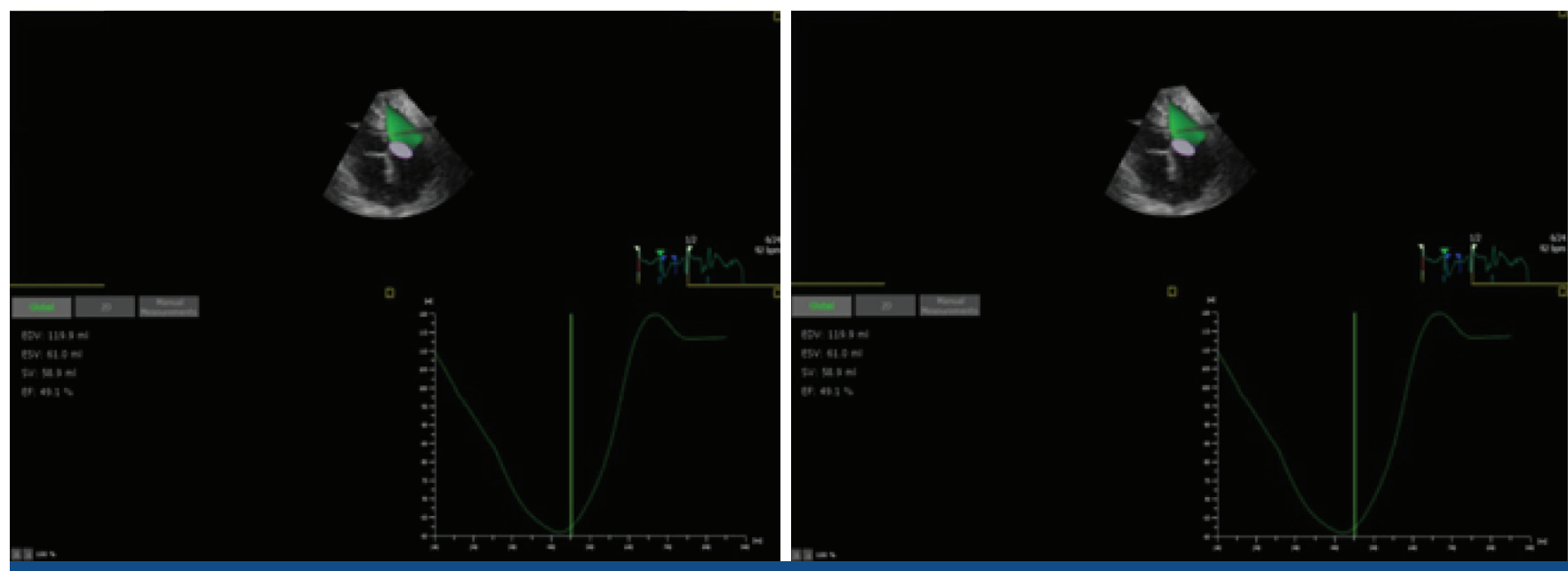

FIGURE 2. The same case in a chronic phase and with improvement in the hemodynamic condition.

Conclusions: Based on the data obtained from our study, we can conclude: 1) In pulmonary PE patients, there is a dilatation RV, which is more accurately quantified with 3D echocardiography, than with 2D echocardiography. 2) Decrease of EF to RV in patients with pulmonary PE was registered. 3) In patients with pulmonary PE, there is a decrease in TAPSE and FAC of RV. 4) The longitudinal strain (LS) of septal and free wall of RV are decreased. 5) We have a much more significant reduction in the LS free wall of RV(LSF), which is one of the PE characteristics. 6) The 2D strain decreases in the middle and apical level of the free wall LS, which is one of the characteristics of the pulmonary PE. 7) In cases of suspicion of pulmonary presence, the regional kinetics of VD, especially the Free wall should be analyzed, which would enable early diagnosis with a high probability.

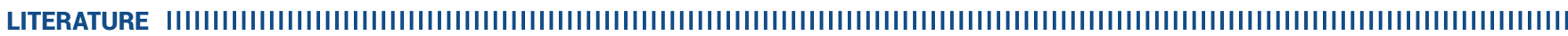

1. Bova C, Greco F, Misuraca G, Serafini O, Crocco F, Greco A, et al. Diagnostic utility of echocardiography in patients with suspected pulmonary embolism. Am J Emerg Med. 2003 May;21(3):180-3. https://doi.org/10.1016/S0735-6757(02)42257-7

2. Casazza F, Bongarzoni A, Capozi A, Agostoni 0. Regional right ventricular dysfunction in acute pulmonary embolism and right ventricular infarction. Eur J Echocardiogr. $2005 \mathrm{Jan} ; 6(1): 11-4$. PubMed: https://www.ncbi.nlm.nih.gov/pubmed/15664548 